\title{
Pelatihan Pembuatan Media Pembelajaran Interaktif Bentuk Presenter-View-Recorder dan Mentimeter
}

\author{
Rafika Sari ${ }^{1}$, Herlawati ${ }^{1{ }^{*}}$, Fata Nidaul Khasanah ${ }^{1}$, Prima Dina Atika ${ }^{1}$ \\ ${ }^{1}$ Fakultas IImu Komputer, Universitas Bhayangkara Jakarta Raya; Jl. Raya Perjuangan no.81 \\ Margamulya, Bekasi Utara, Kota Bekasi; telp 021- 88955882 e-mail: \\ rafika.sari@dsn.ubharajaya.ac.id, herlawati@ubharajaya.ac.id, fatatanidaul@gmail.com, \\ prima.dina@dsn.ubharajaya.ac.id \\ * Korespondensi: email: herlawati@ubharajaya.ac.id
}

Submitted: 15/12/2021; Revised: 18/12/2021; Accepted: 28/12/2021; Published: 31/12/2021

\begin{abstract}
During the Covid-19 pandemic, most educators used social media to deliver learning material files without verbal explanation, unlike face-to-face learning in class. Through these limited facilities, it has an effect between teachers and students experiencing interaction problems which can be used as a benchmark for the absorption of the material provided by the teacher and understanding of the material for students. Based on this problem, we took the initiative to make community service activities by providing training on the use of the Powerpoint PresenterView-Recorder and Interactive Mentimeter applications as interaction media in online learning, which are still rarely used by teachers, especially at SMPN 264 Jakarta. The implementation of this training program aims to provide breakthroughs in teaching. Students are expected not to be bored while participating in learning activities. The innovation used is by optimizing the Powerpoint application in the form of Presenter-View-Recorder as well as using the Interactive Mentimeter application and directly uploading learning videos that have been made to the Google Classroom application and Youtube social media.
\end{abstract}

Keywords: Google Classroom, Mentimeter, Video Presenter-View-Recorder, Youtube

\begin{abstract}
Abstrak
Pada masa pandemi Covid-19 kebanyakan para pendidik memanfaatkan media sosial untuk menyampaikan file materi pembelajaran tanpa disertai penjelasan secara lisan, tidak seperti pada belajar tatap muka dikelas. Melalui sarana yang terbatas tersebut memberikan efek antara guru dan siswa mengalami kendala interaksi yang dapat dijadikan sebagai tolak ukur penyerapan materi yang diberikan guru dan pemahaman materi bagi siswa. Berdasarkan kondisi masalah ini maka kami berinisiatif membuat kegiatan pengabdian kepada masyarakat dengan memberikan pelatihan pemanfaatan aplikasi Powerpoint Presenter-View-Recorder dan Interactive Mentimeter sebagai media interaksi dalam pembelajaran daring, yang masih jarang digunakan oleh para pengajar khususnya di SMPN 264 Jakarta. Pelaksanaan program pelatihan ini bertujuan untuk memberikan terobosan dalam mengajar. Siswa diharapkan tidak bosan saat mengikuti kegiatan belajar. Inovasi yang digunakan adalah dengan mengoptimalkan aplikasi Powerpoint dengan bentuk Presenter-View-Recorder sekaligus penggunaan aplikasi Interactive Mentimeter dan langsung mengupload video pembelajaran yang telah dibuat ke aplikasi Google Classroom dan media sosial Youtube.
\end{abstract}

Kata kunci: Google Classroom, Mentimeter, Video Presenter-View-Recorder, Youtube 


\section{Pendahuluan}

Pesatnya perkembangan teknologi dan informasi dewasa ini dapat membantu guru dan peserta didik menyajikan materi presentasinya dengan mudah dan menarik. Media presentasi sendiri ada bermacam-macam, salah satunya adalah dengan menggunakan aplikasi Microsoft Power Point (Ms.PowerPoint). Ms.PowerPoint sendiri adalah aplikasi yang paling familiar digunakan oleh masyarakat karena biasanya aplikasi ini merupakan aplikasi bawaan yang ada di Notebook/Laptop maupun Personal Computer (PC) bahkan saat ini sudah dapat di instal pada smartphone (Hafizd et al., 2017)

Microsoft Power Point merupakan salah satu program aplikasi Microsoft Office yang berguna untuk membuat presentasi dalam bentuk slide. Aplikasi ini biasanya di gunakan untuk keperluan presentasi, mengajar dan untuk membuat animasi sederhana. Adanya aplikasi Powerpoint, bisa menggantikan cara presentasi konvensional yaitu dengan transparansi proyektor atau sering di sebut dengan OHP (Over Head Proyektor). Karena dengan aplikasi Powerpoint, membuat presentasi bisa menjadi mudah karena di dukung dengan fitur-fitur yang canggih dan menarik (Support Mocrosoft, 2021).

Metode pengajaran pada masa serba daring seperti saat ini, kadang-kadang dianggap monoton dan membosankan, karena kebanyakan pengajar menyampaikan materi hanya dengan mengirimkan file materi ke salah satu media aplikasi belajar tanpa disertai penjelasan secara lisan seperti yang diperoleh bila peserta didik belajar tatap muka dikelas. Hal ini menjadi salah satu penyebab kurang maksimalnya penyerapan dan pemahaman materi yang diperoleh para murid, selain menimbulkan efek siswa menjadi bosan dan kurang antusias dalam belajar. Pelaksanaan program pelatihan ini bertujuan untuk memberikan terobosan dalam mengajar. Siswa diharapkan tidak bosan saat mengikuti kegiatan belajar. Inovasi yang digunakan adalah dengan mengoptimalkan aplikasi Powerpoint dengan bentuk Presenter-View-Recorder sekaligus penggunaan aplikasi Interactive Mentimeter sebagai media interaksi dalam pembelajaran daring.

Salah satu fitur menarik yang masih jarang digunakan dalam presentasi menggunakan Powerpoint adalah Presenter View. Kita dapat menggunakan Microsoft PowerPoint untuk melengkapi presentasi slideshow dan membantu dapat menyesuaikan penjelasan lisan kita dengan slide presentasi yang dikemas dalam bentuk video. PowerPoint Presenter View memberikan kita setidaknya empat tools penting yang membuat tayangan presentasi slide menjadi lebih nyaman dan menarik (Childress, 2017)

Guru-guru dan siswa siswi SMP Negeri 264 Jakarta akan menjadi mitra dalam kegiatan pengabdian masyarakat ini. Pihak guru dalam menyampaikan materi pelajaran di awal masa pandemi Covid-19 adalah hanya memanfaatkan media sosial Whatsapp untuk membantu dalam penyampaian materi kegiatan belajar. Namun melalui media tersebut antara guru dan siswa mengalami kendala terkait interaksi yang dapat dijadikan sebagai tolak ukur bagaimana penyampaian materi yang diberikan guru dan pemahaman materi bagi siswa. Berdasarkan kondisi masalah yang terjadi pada pihak mitra tersebut maka dibuatlah kegiatan pengabdian 
kepada masyarakat ini, yaitu dengan memberikan pelatihan pemanfaatan aplikasi Powerpoint Presenter-View-Recorder dan Interactive Mentimeter sebagai media interaksi dalam pembelajaran daring.

\section{Metode Pelaksanaan}

Kegiatan pengabdian kepada masyarakat dengan pihak mitra yaitu SMP Negeri 264 Jakarta menggunakan metode yang terdiri dari beberapa tahap kegiatan pelaksanaan yaitu: (i) tahap pertama dengan melakukan kegiatan koordinasi dalam hal ini penyuluhan pendahuluan terhadap pihak mitra, (ii) tahap kedua yaitu kegiatan pelaksanaan pelatihan secara daring dan (iii) tahap terakhir adalah kegiatan pendampingan dalam hal ini kelanjutan penerapan di pihak mitra tentang evaluasi pembuatan media pembelajaran berbasis Powerpoint dalam bentuk presenter-view-recorder yang direncanakan akan ada uji coba pembelajaran langsung secara langsung menggunakan aplikasi video conference dan di upload pada aplikasi Google Classroom dan media sosial Youtube.

Setelah berkoordinasi dengan pihak mitra, kegiatan pelatihan ini dilakukan dengan pihak mitra untuk membahas materi yang akan disampaikan, tanggal pelaksanaan dan peserta yang akan mengikuti pelatihan ini. Tujuan dari kegiatan ini adalah agar pihak mitra dapat menggunakan aplikasi Powerpoint dalam bentuk presenter-view-recorder sebagai media penyampaian materi secara daring agar optimal sebagai salah satu alternatif dalam pembuatan media pembelajaran interaktif. Sehingga dari kegiatan pengabdian kepada masyarakat ini dapat memberikan manfaat bagi pihak mitra dalam memanfaatkan peranan teknologi terkini terkait pembuatan media pembelajaran interaktif yaitu aplikasi Powerpoint dalam bentuk presenterview-recorder yang dianggap lebih mudah dalam hal penggunaan atau pembuatan video pembelajaran dibandingkan dengan aplikasi video maker lainnya, guna mendukung kegiatan pembelajaran yang saat ini akan dilakukan secara daring atau online dalam mendukung program pemerintah merdeka belajar.

Kegiatan pelatihan dilaksanakan secara daring dikarenakan masih dalam kondisi pandemi Covid-19 yang tidak memungkinkan adanya kegiatan pertemuan yang dilakukan secara berkelompok dalam jumlah banyak. Oleh karena itu kegiatan pelatihan dilaksanakan secara online dengan melakukan video conference secara langsung melalui aplikasi Zoom atau Google Meet.

Untuk informasi sosialisasi kegiatan pelatihan ini kepada pihak peserta direncanakan akan disebarkan secara broadcast oleh pihak stuktural sekolah melalui jejaring aplikasi Whatshapp ke seluruh civitas SMPN 264 Jakarta. Pada pelatihan ini dijelaskan beberapa materi yang berhubungan dengan pemanfaatan aplikasi Powerpoint dalam pembuatan video pembelajaran dalam bentuk presenter-view-recorder dan menyisipkan slide Interactive Mentimeter sebagai media interaktif dalam kegiatan pembelajaran yang dilakukan secara daring atau online. Dalam tahap akhir dilakukan kegiatan pendampingan untuk mendampingi pihak sekolah dalam hal ini guru dan siswa, dimana guru akan mencoba mengimplementasikan hasil 
dari materi pelatihan yang telah disampaikan langsung secara langsung menggunakan aplikasi video conference dan di upload pada aplikasi Google Classroom dan media sosial Youtube. Gambar 2 merupakan bagan tahapan penyampaian materi pelatihan.
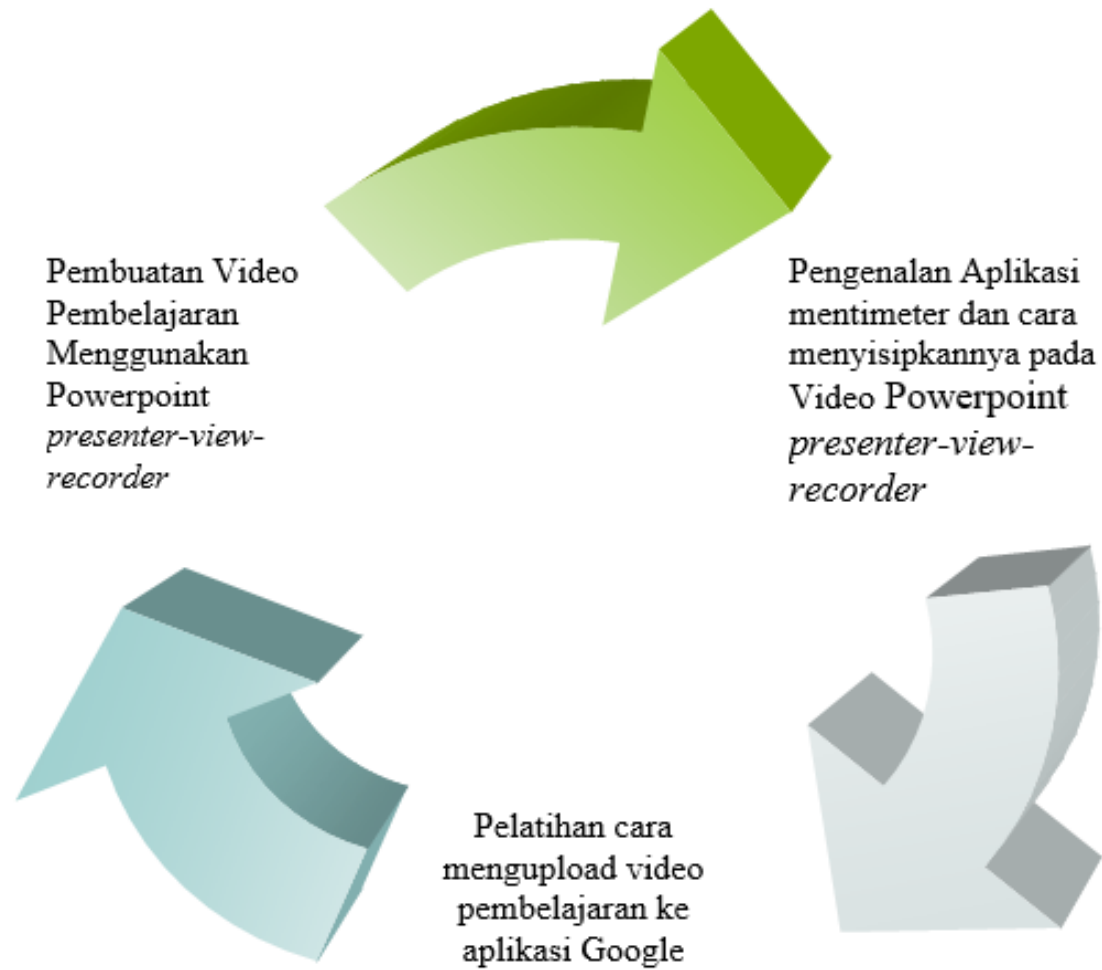

Pelatihan cara mengupload video pembelajaran ke aplikasi Google

Classroom dan Media

Sosial YouTube

Sumber: Hasil Pelaksanaan (2021)

Gambar 1. Bagan Tahapan Penyampaian Materi Pelatihan

\section{Hasil dan Pembahasan}

\subsection{Pembuatan Video Presenter-View-Recorder Ms. Power Point}

Berikut adalah tahapan pembuatan video pembelajaran menggunakna fitur presenterview-recorder yang sudah disediakan oleh Ms. Power Point, antara lain a) Siapkan materi bahan ajar berupa file PowerPoint (ppt) yang sudah dibuat; b) Buka file PowerPoint tersebut; c) Pilih menu Slide Show $\rightarrow$ Record Slide Show; d) Pilih salah satu: Record form Current Slide atau Record from Biginning; e) Record form Current Slide: Untuk merekap hanya slide yang sedang ditayangkan. Record from Biginning : Untuk merekam keseluruhan slide dari awal hingga akhir; f) Setelah itu muncul tampilan recording seperti gambar dibawah ini, kemudian pilih menu Setting; g) Setting $\rightarrow$ atur Camera dan Microphone; h) Berikut tampilan gambar saat alan merekam video; i) Mulai merekap $\rightarrow$ Klik Record; j) Klik tombol next untuk recording penjelasan ke slide berikutnya; k) Bisa memanfaatkan menu pada Pointer Option untuk bantuan memberikan kursor/tulisan penjelasan saat menerangkan; I) Bisa pula menggunakan 
fitur timing pada setiap slide, berfungsi time-keeper saat melakukan perekaman/recording agar durasi waktu dapat sesuai dengan yang kita inginkan; $\mathbf{m}$ ) Proses recording pada masingmasing slide bisa di hapus dan direkam ulang tanpa menghapus recording pada slide-slide sebelumnya; n) Dapat pula hanya merekam audio saja tanpa disertai video atau sebaliknya, dengan mengklik icon kamera atau microphone pada bagian pojok kanan bawah; o) Setelah semua recording slide telah dijelaskan/dipaparkan, maka untuk mengakhiri proses recording cukup mengklik tanda $X$ pada bagian pojok kanan atas layer; p) Silahkan bisa mengatur posisi/letak presenter-view pada masing-masing slide, ukurannya pun dapat disesuaikan; q) Tampilan gambar presenter-view pada masing-masing slide dapat di edit pada menu Format; $\mathbf{r}$ ) Setelah proses editing selesai, simpan file recording $\rightarrow$ File $\rightarrow$ Save as $\rightarrow$ pilih folder penyimpanan $\rightarrow$ tulis nama file $\rightarrow$ Save as Type MPEG 4 Video; s) Tunggu hingga proses saving selesai $\rightarrow$ lihat progress penyimpanan pada bagian bawah slide; t) Setelah proses saving selesai berarti file video Powerpoint telah siap digunakan.
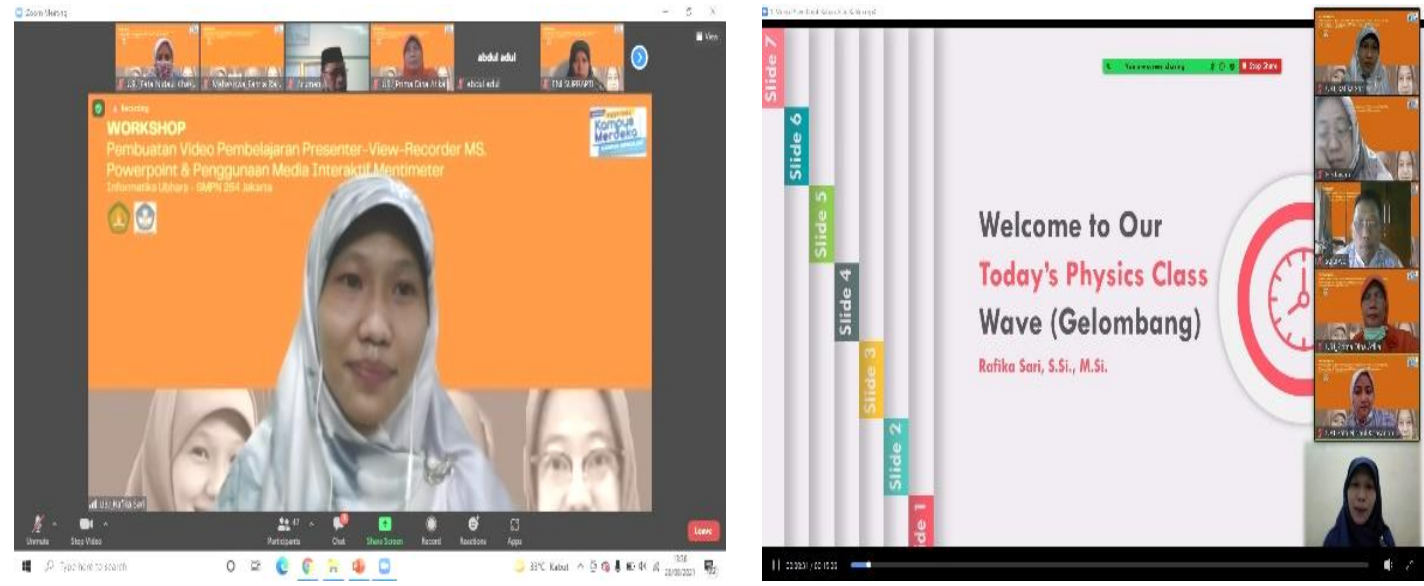

Sumber: Hasil Pelaksanaan (2021)

Gambar 1. Dokumentasi Pelatihan Pembuatan Video Pembelajaran

\subsection{Pembuatan Slide Presentasi Mentimeter}

Saat ini, dengan perkembangan teknologi seluler dan koneksi internet yang meluas, cakupan elearning mengalami perkembangan ke arah teknologi seluler, dalam hal ini smartphone. Terlebih pada masa pandemi Covid-19 seperti sekarang ini, hampir sebagian besar pelajar menggunakan smartphone dalam mendukung kegiatan pembelajaran daring. Sehingga aplikasi-aplikasi presentasi yang menarik, interakti dan mudah diakses melalui smartphone menjadi hal yang penting untuk menciptakan suasana pembelajaran daring yang menyenangkan. Aplikasi Mentimeter menjadi salah satu solusi dalam menciptakan hal tersebut. Mentimeter merupakan aplikasi presentasi interaktif berbasis web, yang memiliki lebih dari 30 juta pengguna di lebih dari 120 negara. Mentimeter merupakan aplikasi perancangan interaktif agar presentasi menjadi menarik dan menghibur. Selain itu mentimeter juga dapat digunakan untuk survey, kuis, cloud kata, presentasi gambar dan grafik. Dengan Mentimeter, interaksi antara presenter (dalam hal ini guru) dan audiens (peserta didik) dapat disajikan dalam 
presentasi dengan fitur memberikan umpan balik langsung (feedback) melalui smartphone, tablet, PC atau laptop (Gokbulut 2020).

Cara kerja Mentimeter adalah apabila presenter atau instruktur mempublikasikan presentasi melalui www.mentimeter.com, sistem Mentimeter menghasilkan kode pin untuk dimasuki peserta. Kemudian peserta didik dapat berpartisipasi langsung dengan masuk ke dalam sistem Mentimeter dan memasukkan kode pin di www.menti.com. Sistem diakses hanya dengan kode pin, dan tidak ada informasi lain dari pelajar yang dimasukkan ke dalam sistem. Setelah pelajar masuk ke sistem, jawaban yang mereka berikan ke aplikasi segera dijangkau dan dihasilkan secara real time oleh guru dan teman-teman mereka. Sementara informasi pribadi apa pun dari siswa tidak tercermin di layar sistem, sehingga siswa yang memiliki kemampuan pasif dan rasa malu pada teman sebaya di kelas dapat partisipasi aktif dan termotivasi karena turut berkesempatan berpartisipasi akti di kelas. Gambar 4 (a-d) merupakan dokumentasi dari pelatihan Mentimeter pada sesi 1 dengan sesi 3 yaitu pengenalan Mentimeter, membuar presentasi Mentimeter dan menyisipkan slide Mentimeter pada slide Powerpoint, yang masing-masing disampaikan oleh pemateri pertama, kedua dan ketiga.
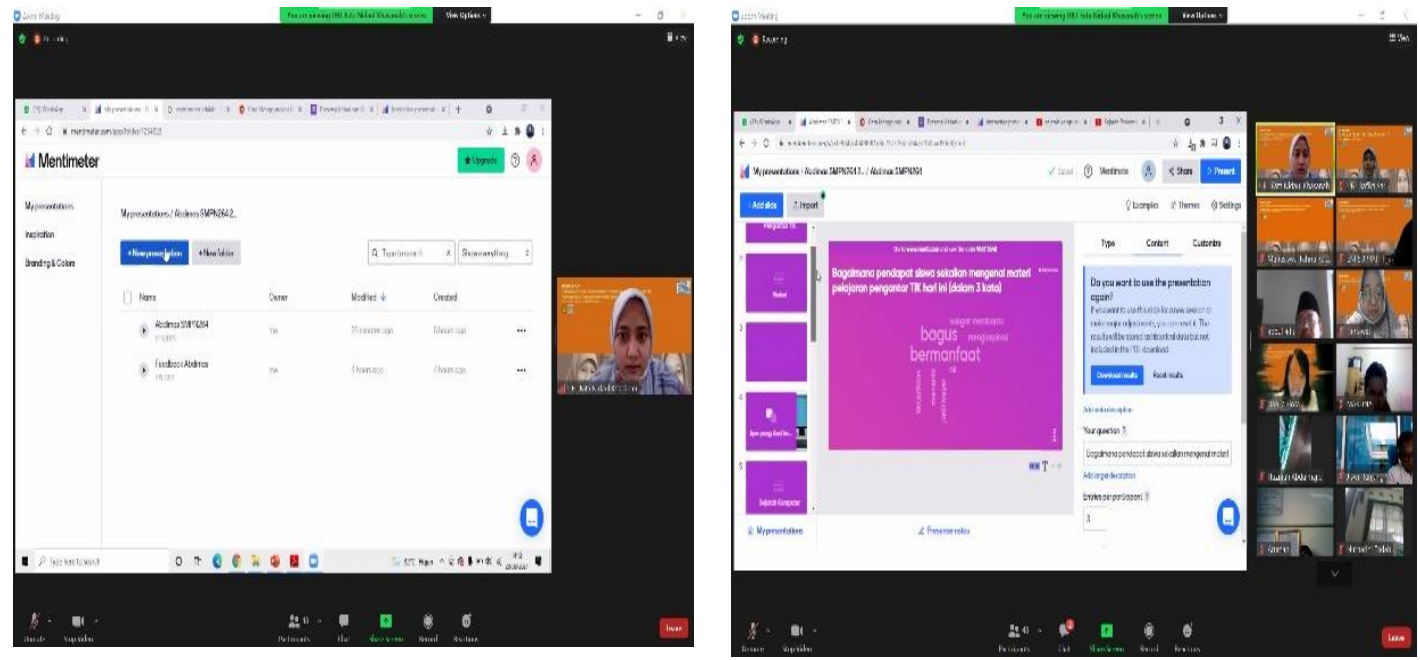

Sumber: Hasil Pelaksanaan (2021)

Gambar 2. Dokumentasi Kegiatan Materi Mentimeter

Pada sesi kedua pada pelatihan ini, dilakukan praktek langsung membuat presentasi menggunakan Mentimeter. Beberapa menu dan fitur pada Mentimeter disampaikan pada pelatihan ini. Menu utama pada aplikasi ini, yaitu Type, Content dan Customize. Terdapat submenu lagi pada masing-masing menu tersebut, untuk menu Type terdapat pilihan untuk memodifikasi tampilan slide, yaitu (Herlawati, dkk., 2021) a) Popular question types, terdapat beberapa pilihan penyajian berupa Multiple choice, Word cloud, Open Enden, Scale, Rangking dan Q\&A (Question and Answer); b) Quiz Competition, terdapat beberapa pilihan cara menjawab quis yaitu Select answer dan Type answer; c) Content slide, terdapat beberapa pilihan penyajian yaitu Heading, Paragraph, Bullets, Image, Video, Big, Quote, dan Number; d) Advanced questions, terdapat beberapa pilihan penyajian yaitu: 100 points, 2×2 Grid, Quick form, dan Who will win? 
Seperti yang terlihat pada gambar 3.3(a), tampilan paling kiri merupakan tampilan slide yang sedang dimodifikasi, dan layar sebelah kanan merupakan perbandingan tampilan layar presenter (kiri) dan tampilan layar audiens.

Pada menu Content berisi fitur setting atau editing untuk masing-masing menu Type yang dipilih. Sedangkan pada menu Customize berisi menu setting antara lain: (i) setting slide yang berisi pilihan pengaturan close voting, hide intructions bar, hide result, (ii) layout, (iii) image, (iv) advanced layout, (v) advanced color. Untuk pilihan (iv) dan (v) hanya tersedia untuk akun berbayar (Mentimeter pro). Selain tiga menu utama yang telah disebutkan diatas, terdapat juga menu Example, Theme, dan Configure. Ketiga menu pengaturan utama ini diberlakukan untuk semua slide yang sedang kita buat. Sedangkan menu/fitur yang dijelaskan sebelumnya hanya untuk pengaturan tiap halaman slide. Seperti yang terlihat pada gambar 5(a) merupakan tampilan Mentimeter setelah kita melakukan login, kemudian slide yang dibuat merupakan jenis popular question type dengan menyisipkan gambar yang sesuai dengan pertanyaan yang kita ajukan. Sedangkan gambar 5(b) merupakan tampilan slide dengan jenis multiple choice (sebelah kiri) dan tampilan menti.com (sebelah kanan) yaitu laman untuk mengakses presentasi yang kita buat, dengan memasukkan kode presentasi bagi para audiens yang ingin berpartisipasi (Mentimeter, 2021). Gambar 4 merupakan dokumentasi pelaksanaan pelatihan penggunaan mentimeter.

\subsection{Mengupload Video ke Platform Google Classroom dan YouTube}

Beberapa cara mengirim atau mengupload video pada Google Classroom. Kita dapat mencobanya dengan langsung merekam video dan kemudian kirim ke Google Classroom. Atau kita bisa membuat video terlebih dahulu dan disimpan di Google Drive atau Youtube, lalu linknya yang kita upload ke Google Classroom. Mengirim video pada Google Classroom ini biasanya dipakai oleh siswa untuk mengerjakan tugas yang diberikan oleh guru. Gambar 3 merupakan dokumentasi pelaksanaan pelatihan cara mengupload video ke platform Google Classroom dan sosial media YouTube. Berikut adalah tahapan yang dilakukan bila ingin mengupload video pembelajaran ke media sosial YouTube (Tribun, 2021): a) Login ke YouTube; b) Di bagian atas halaman, klik Upload; c) Pilih Upload video; d) Sebelum mulai mengupload video, dapat memilih setelan privasi video; e) Pilih video yang ingin diupload dari komputer atau perangkat yang sedang digunakan. Dapat mengimpor video dari Google Foto; f) Saat video diupload, kita dapat mengedit informasi dasar dan setelan lanjutan untuk video tersebut, serta menentukan apakah ingin mengirimkan notifikasi kepada subscriber atau tidak (jika kamu menghapus centang opsi ini, subscriber tidak akan mendapatkan notifikasi). Partner juga dapat menyesuaikan setelan Monetisasi. Kamu dapat membuat judul video dengan panjang hingga 100 karakter dan deskripsi hingga 5.000 karakter; g) Klik Publikasikan untuk menyelesaikan proses upload video publik ke YouTube. Jika kita mengatur setelan privasi video ke Pribadi (private) atau Tidak Publik, cukup klik Selesai untuk menyelesaikan upload, atau klik Bagikan untuk berbagi video secara pribadi; $\mathbf{h}$ ) Jika kita belum mengklik Publikasikan, video 
tidak dapat dilihat orang lain. Kamu dapat memublikasikan video kapan saja di Pengelola Video.

Sedangkan tahapan untuk mengupload video pembelajaran ke platform Learning Management System (LMS) Google Classroom adalah sebagai berikut : (Carago, 2021) a) Pertama kalian dapat membuka aplikasi Google Clasroom terlebih dahulu; b) Selanjutnya klik tugas yang diberikan oleh guru dan pilih Silahkan di upload tugas video melalui Google Classroom; c) Swipe ke atas untuk menemukan Add Attachment. Lalu klik Add Attachment d) Setelah itu tersedia pilihan mulai dari Drive, Link dan File. Disini kalian dapat pilih File; e) Klik Garis tiga di bagian pojok kiri atas; f) Klik Video dan pilih video yang akan dikirim; g) Tunggu video diupload dan klik Turn In; $\mathbf{h}$ ) Selamat, video kalian telah terkirim.
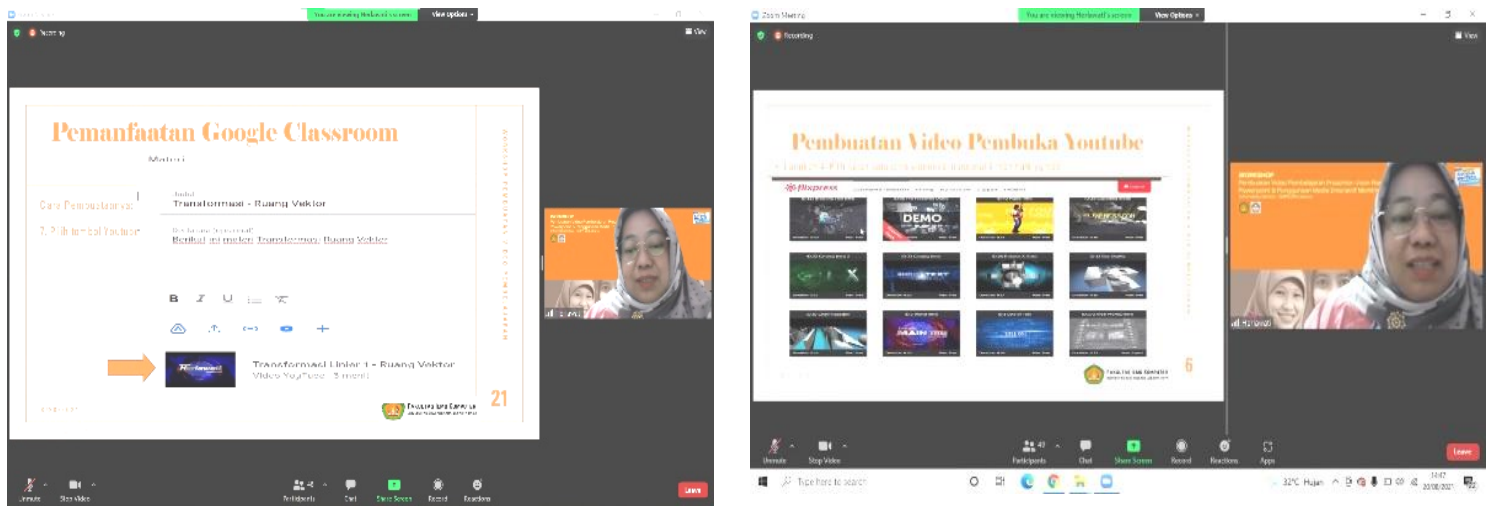

Sumber: Hasil Pelaksanaan (2021)

Gambar 3. Dokumentasi Cara Upload Video Pembelajaran Ke Google Classroom Dan Youtube

Semua kegiatan yang dilakukan dalam pelatihan ini ditujukan agar para guru dapat mendesain penyajian materi pembelajaran secara individual sehingga dapat mendukung kebutuhan guru dalam persiapan pembelajaran daring maupun luring (tatap muka) dengan baik dan lebih inovatif. Hasil survey kepuasan atas pelatihan ini dilakukan pada akhir acara dengan langsung menerapkan aplikasi Mentimeter sebagai sarana survey. Gambar 6 memperlihatkan hasil survey dan masukan terhadap kegiatan pelatihan yang merupakan bentuk pengabdian masyarakat dari program studi Informatika, Universitas Bahayangkara Jakara Raya (UBJ). Survey dilakukan dengan mengajukan dua buah pertanyaan, pertanyaan pertama yaitu pendapat mengenai pelatihan membuat media pembelajaran menggunakan Mentimeter yang disajikan dalam bentuk word-cloud, dan pertanyaan kedua mengenai isi ketiga meteri pelatihan yang telah disampaikan dan disajikan dalam bentuk scale. Hasil survey menjadi bahan evaluasi terhadap kebutuhan pelatihan semacam ini baik bagi pihak mitra yaitu SMAN 14 bekasi maupun bagi pihak penyelenggara yaitu Prodi Informatika UBJ. Hasil analisa menunjukkan bahwa sebagian besar peserta memberikan tanggapan positif terhadap program pelatihan ini. Beberapa masukan dari peserta yang disampaikan secara langsung baik lisan maupun tulisan yaitu, dilakukan pelatihan kembali yang dilakukan secara offline agar para peserta bisa mempraktekan dan berdiskusi lebih optimal, dan waktu pelatihan yang dibuat menjadi beberapa kali pertemuan. 

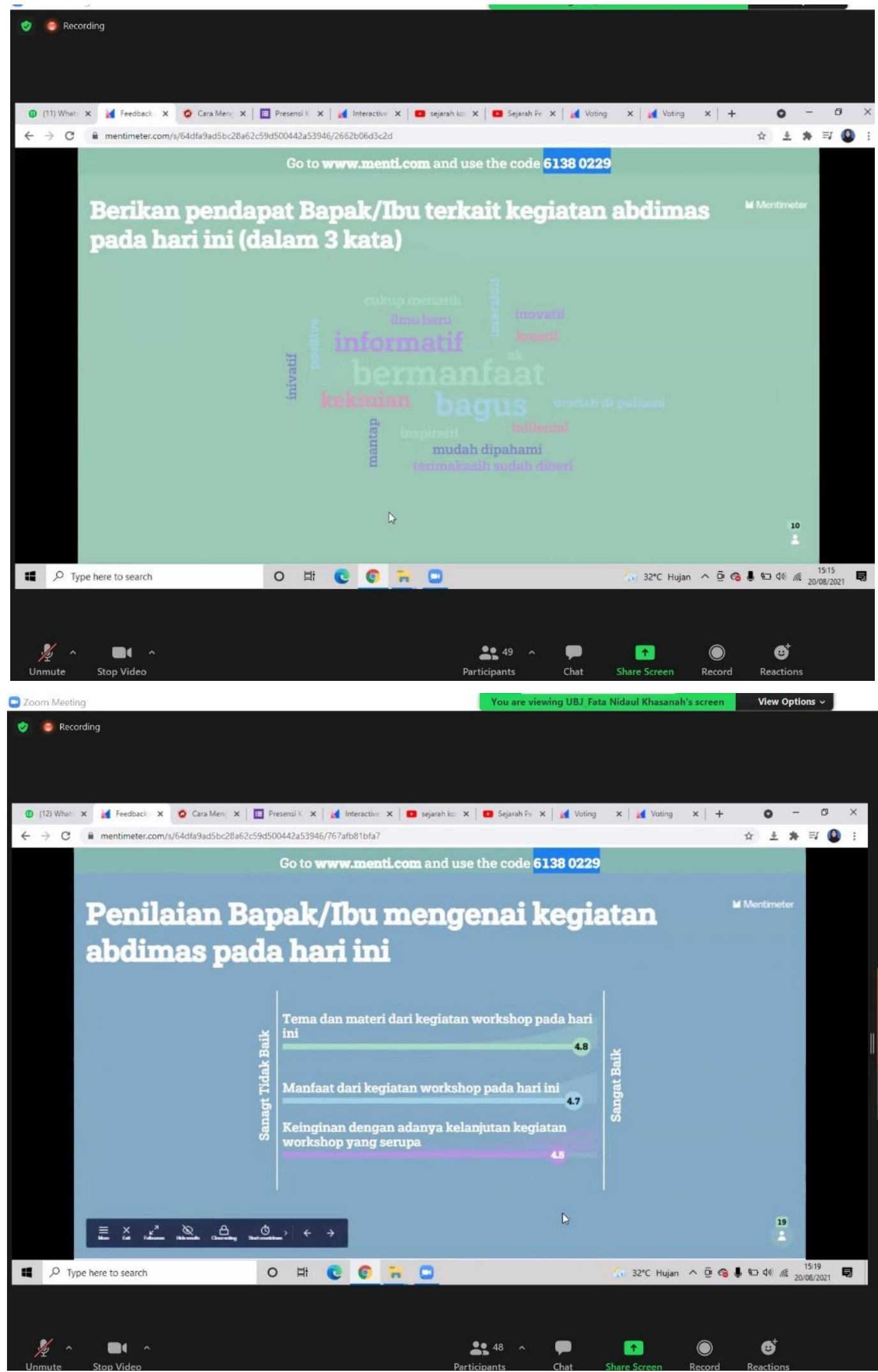

Sumber: Hasil Pelaksanaan (2021)

Gambar 4. Tampilan Feedback Acara Dari Peserta Menggunakan Aplikasi Menti.Com 
Hasil survey diatas ataupun menu lainnya yang kita pilih pada aplikasi Mentimeter akan diakumulasikan secara otomatis dan realtime serta dapat di download dalam bentuk file pdf. Tampilan Leaderboard pada layar presenter akan sama dengan hasil download result pada file pdf tersebut. Gambar 7 merupakan dokumentasi kegiatan penyerahan plakat dan cenderamata serta penyampaian laporan dan evaluasi kegiatan kepada pihak sekolah SMPN 264 Jakarta.
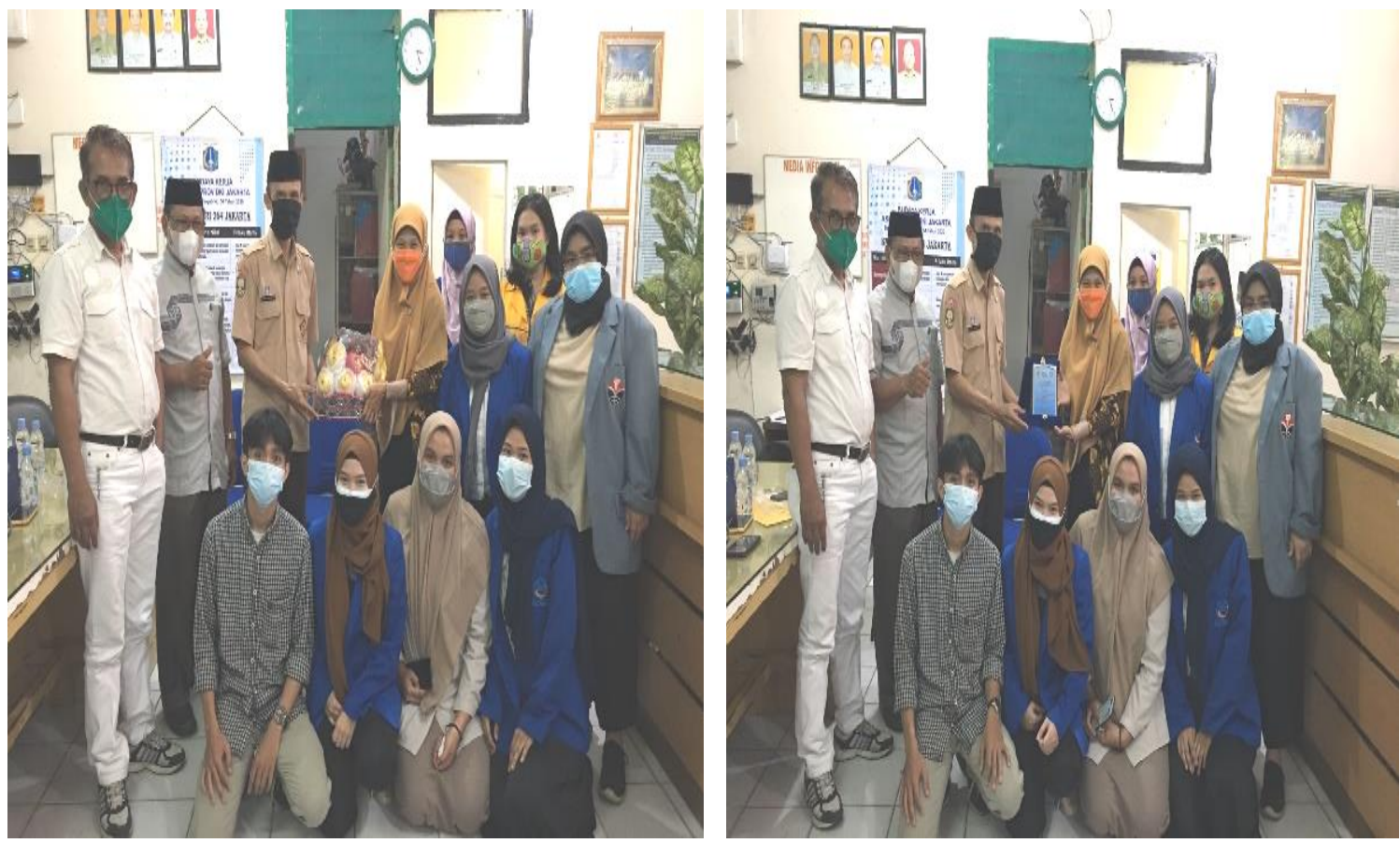

Sumber: Hasil Pelaksanaan (2021)

Gambar 5. Dokumentasi Penyerahan Bingkisan dan Plakat Plakat Program PkM Kepada Pihak SMPN 264

\section{Kesimpulan}

Dari kegiatan pengabdian masyarakat yang telah kami laksanakan di SMPN 264 Jakarta maka dapat disimpulkan bahwa seiring dengan perkembangan teknologi, membuat perubahan dalam lingkungan belajar. Keikursertaan teknologi dalam kegiatan belajar mengajar (KBM) menjadi penting dalam merancang elearning interaktif di dalam dan di luar kelas. Salah satu faktor untuk mempercepat transformasi ini adalah dengan memanfaatkan berbagai aplikasi dalam penyajian bahan ajar, salah satunya adalah fitur pembuatan video presenter-viewrecorder pada Ms. Power Point dan penggunaan media interaktif Mentimeter. Pada program pelatihan ini, fitur pembuatan video yang telah disediakan oleh Ms. Power Point dan aplikasi Mentimeter sangat mendukung metode pembelajaran elearning dari seorang guru yang mengadakan (KBM) baik saat kelas daring maupun tatap muka. Sebagai hasil dari pelatihan ini, diamati bahwa aplikasi Mentimeter berpengaruh besar pada disposisi elearning guru dalam KBM daring. Dengan penyajian bajan ajar berupa video yang dapat diakses pada berbagai Learning Management System (LMS) dalam hal ini Google Classroom atau pun sosial media (YouTube), siswa mendapatkan lebih banyak manfaat dari alat digital dan langsung berinteraksi dengan konten yang mereka pelajari (Skoyles and Bloxsidge 2017). 


\section{Ucapan Terima Kasih (Opsional)}

Ucapan terima kasih kami sampaikan kepada LPPMP Universitas Bhayangkara Jakarta Raya sebagai pihak yang telah memberikan hibah dalam pelaksaaan kegiatan pengabdian masyarakat ini, dan juga kepada sekolah SMPN 264 Jakarta sebagai pihak mitra dalam program pengabdian kepada masyarakat ini.

\section{Daftar Pustaka}

"6 Cara Mengirim Video Di Google Classroom Paling Mudah 2021 | Carago." https://www.carago.id/cara-mengirim-video-di-google-classroom/ (September 6, 2021).

"8 Cara Mudah Mengunggah Atau Mengupload Video Ke YouTube Lewat Komputer, HP Android Dan IPhone - Tribun Jatim." https://jatim.tribunnews.com/2019/06/05/8-caramudah-mengunggah-atau-mengupload-video-ke-youtube-lewat-komputer-hp-android-daniphone (September 6, 2021).

Bielinis, Lidia. "Why Do You Want Me To Learn Connectively But Test Me Individually? Socially Embedded Learning At The University." I: 39-56. http://dx.doi.org/10.17770/sie2018vol1.3245 (January 2, 2021).

Childress, Andrew. "Cara Mempresentasikan PowerPoint Slideshow Dengan Presenter View." https://business.tutsplus.com/id/tutorials/powerpoint-presenter-view--cms-29671 (April 20, 2021).

Gokbulut, Bayram. 2020. "The Effect of Mentimeter and Kahoot Applications on University Students' e-Learning." World Journal on Educational Technology: Current Issues 12(2): 107.

Hafizd, Khairul Anwar et al. "Pelatihan Penggunaan Media Pembelajaran Dengan Aplikasi Microsoft Power Point." : 2-5.

Herlawati, Fata Nidaul Khasanah, and Rafika Sari. 2021. "Pelatihan Mentimeter Sebagai Media Interaksi Dalam Pembelajaran Daring Pada SMAN 14 Bekasi." Journal Of Computer Science Contributions (JUCOSCO) 1(1): 42-52.

"Interactive Presentation Software - Mentimeter." https://www.mentimeter.com/ (December 28, 2020).

Skoyles, Alison, and Erin Bloxsidge. 2017. "Have You Voted? Teaching OSCOLA with Mentimeter." Legal Information 17. https://heinonline.org/HOL/Page?handle=hein.journals/leginfom17\&id=254\&div=\&collectio $\mathrm{n}=($ January 2,2021$)$. 
Support, Microsoft. "Merekam Peragaan Slide Dengan Pengaturan Waktu Slide Dan Narasi Dukungan Office." https://support.microsoft.com/id-id/office/merekam-peragaan-slidedengan-pengaturan-waktu-slide-dan-narasi-0b9502c6-5f6c-40ae-b1e7-e47d8741161c (April 20, 2021). 